Egyptian Journal of Aquatic Biology \& Fisheries

Zoology Department, Faculty of Science,

Ain Shams University, Cairo, Egypt.

ISSN $1110-6131$

Vol. 24(1): $623-637$ (2020)

www.ejabf.journals.ekb.eg

\title{
Synthesis and Characterization of Chitosan-Amidoxime Chelating Resin (CACR) and Application for lead Removal from Aqueous Medium
}

\author{
Alaa E. Amin ${ }^{1, *}$; Mohamed E. Goher ${ }^{2}$; Amr S. El-Shamy ${ }^{2}$ and \\ Abdel-Wahed S. Abdel-Wahed ${ }^{3}$ \\ 1- Chemistry Department, Faculty of sciences, Benha University, El Qaliobia, Egypt \\ 2- National Institute of Oceanography and Fisheries (NIOF), Cairo, Egypt \\ 3- El Nasr Co. for intermediate Chemicals (NCIC), Egypt. \\ *Corresponding author: smgoher@yahoo.com
}

\section{ARTICLE INFO \\ Article History: \\ Received: Feb. 22, 2020 \\ Accepted: March 4,2020 \\ Online: March 7, 2020}

Keywords:

Chitosan,

lead removal

adsorption process

Langmuir and Freundlich

isotherms.

\begin{abstract}
This study deals with new modified chitosan beads with pendent amidoxime moieties [chitosan amidoxime chelating resin (CACR)] prepared by reaction of cross-linking chitosan beads with acrylonitrile and hydroxylamine. The resulting (CACR) resin was characterized using Fourier transform infrared, energy dispersive X-ray analysis, Scanning Electron Microscopy and BET surface area. To remove lead ions from aqueous solution the study was carried out under several variables include the initial concentration $(50-250 \mathrm{mg} / \mathrm{L})$, the amount of CACR $(1-5 \mathrm{~g} / \mathrm{L})$, contact time (10-300 $\mathrm{min})$ and the $\mathrm{pH}$ value (1.5-3.5) to indicate the removal efficiency of the (CACR). Glutaraldehyde. The batch experiment cited that the maximum adsorption efficiency of $55.5 \mathrm{mg} / \mathrm{g}$ was recorded at the optimum conditions of $\mathrm{pH} 3,200 \mathrm{mg} / \mathrm{L}$ of $\mathrm{Pb}$ ions concentration and contact time $120 \mathrm{~min}$. using $2 \mathrm{~g} / \mathrm{L}$ of [CACR]. The adsorption of lead ions with [CACR] follows the pseudo-second-order kinetics. The adsorption process was fitted to Langmuir and Freundlich isotherms models with slight advantage for the Langmuir approach.
\end{abstract}

\section{INTRODUCTION}

Wastewater containing heavy metals originated mainly from metal plating facilities, mining operations, fertilizer industries, tanneries, batteries, paper industries and pesticides galvanizing plants, stabilizers, thermoplastics, pigment manufacture, etc (Yadla et al. 2012). These industries discharge heavy metals and wastewater directly or indirectly into the environment especially in developing countries. Due to their toxicity and non- biodegradability, they tend to accumulate in living organism. Therefore they cause numerous diseases and disorders. Zinc, copper, nickel, mercury, cadmium, lead and chromium are considered as toxic metals of particular concern in wastewater treatment. Thus, treatment of industrial wastewater containing soluble heavy metals has become essential in order to increase the quality of water (Saha et al. 2008). Industrial complexes have now become foci of environmental pollution. The control of these toxic priority pollutants is to be based on the application of the best available technology economically achievable. Metals of particular concern in treatment of industrial wastewaters include $\mathrm{Fe}^{+2}, \mathrm{Mn}^{+2}, \mathrm{Cu}^{+2}, \mathrm{Zn}^{+2}, \mathrm{Ni}^{+2}, \mathrm{~Pb}^{+2}$, and 
$\mathrm{Cd}^{+2}$ which are toxic to living organisms at fairly low concentrations and tend to either biologically magnify or accumulate in plant and animal systems. Thus, the disposal of heavy metals bearing wastes into water bodies or on land is of great concern due to their adverse effects. In general, to be removed from wastewater, the metals must be precipitated or otherwise attached to an insoluble form through nanoparticles adsorbents (Kurniawan et al. 2006; Lakherwal, 2014 and Lalhruaitluanga et al. 2010).

Lead is one of the common contaminants of industrial wastewaters. Lead pollution exists in aqueous waste streams of many industries such as manufacture of storage batteries, printing, painting, pigments, dying, leaded glass (Patterson, 1985 and Ramos et al. 2002). Lead poisoning causes various health hazards, such as damage to liver, kidney and reduction in hemoglobin formation, mental retardation, infertility and abnormalities in pregnant women (WHO, 2011 and Nadeem et al. 2005). Unlike organic compounds, lead is non-biodegradable and accumulates in living organism, therefore, must be removed from water and wastewater. Various methods of lead removal from wastewater have been applied including chemical precipitation, membrane processes, ion-exchange and adsorption. One of the most effective methods for the treatment of heavy metals from aqueous solution has been based on adsorption using low-cost adsorbents (Curkovic et al. 1997 and Bailey et al. 1999).

Chitosan is a unique basic polysaccharide and partially deacetylated polymer of glucosamine obtained after alkaline deacetylation of the chitin (Karthikeyan et al. 2004). It contains reactive amino groups, which selectively binds to all transition metal ions and not binds to alkali and alkaline metal ions and it has been extensively studied for metal ions adsorption (Al-Wakeel, et al. 2015). Chitin consists of mainly of $\beta$-(1-4-2- acetamido-2-deoxy-D-glucose) units and is the second most abundant biopolymer on earth after cellulose. It is widely distributed in crustacean shells and cell walls of fungus (Pentari et al. 2010 and Wana et al. 2010). Chitosan is soluble in dilute acids. The solubilization occurs by the protonation of the $-\mathrm{NH}_{2}$ function on the C-2 position of the D-glucosamine repeat unit, where the polysaccharide is converted to a polyelectrolyte in acidic media (Ramya et al. 2011a and Ramya et al. 2011b). The chelation ability is directly affected by the chelating group and the polymeric matrix. One of the significantproperties of chelating resins is that it's intensive presence in many countries, also their great sorption ability for metal ions enabled them to spread in many applications like [separation of mixtures containing more than one metal] which may be present in low concentration in solution (Khalil, et al. 2014). Glutaraldehyde (GLA) is the most frequently used cross-linking agent as it is capable in preventing the dissolution of chitosan in acidic solution. Although the stability of the cross-linked chitosan was improved, this cross-linking process decreases the number of amino groups, resulting in a decrease in the adsorption capacity. Currently, other alternatively modifications have been performed to improve the chemical stability without losing the adsorption capacity of chitosan (Bingjie, et al. 2013). Chitosan being a linear polyelectrolyte at acidic pH is capable of forming electrostatic complexes with synthetic or natural polyelectrolyte especially alginate. Alginate is derived from brown algae and it comprises of two repeating carboxylate monosaccharide units. Chitosan and alginate can be blended to form polyelectrolyte complex through ionic interaction between the protonated amines on chitosan and carboxylate moieties found on alginate. This interaction forms a three dimensional matrix, and the beads are known as physically cross-linked. This polyelectrolyte complex has a wide range of usage in the medical and biological field 
(Wan Ngah and Hanafiah, 2008). The main objective of this study was to remove lead from aqueous medium using newly developed (CACR). Isotherm and kinetic studies were used to quantify the adsorption process.

\section{MATERIALS AND METHODS}

\section{Chemicals and Preparations:}

Chitosan (de-acetylation degree 93\%) was purchased from Oxford Lab Chem (India), glutaraldehyde (GA), acrylonitrile (AN), acetic acid (AA), liquid paraffin (LP), and hydroxylamine hydrochloride were purchased from Alpha ChemiKa (India) and were used directly. Metal salts were pure grade products of Nice Chemicals Pvt. Ltd., (India) were used as source for $\mathrm{Pb}^{2+}$. De-ionized distilled water was used though the experiment.

\section{Preparation of cross-linked chitosan beads (CLCB):}

Cross-linked chitosan beads were prepared according to the method described by Wang et al. (2010). In brief, $10.0 \mathrm{~g}$ of chitosan was dissolved in $200 \mathrm{ml}$ aqueous solution of acetic acid (3\%) for $48 \mathrm{~h}$ and then added to a $1000 \mathrm{ml}$ beaker flask containing $200 \mathrm{ml}$ of liquid paraffin, continuously stirred for $20 \mathrm{~min}$ at $40{ }^{\circ} \mathrm{C}$ After that, the temperature was increased to $60{ }^{\circ} \mathrm{C}$, and $10 \mathrm{ml}$ of $(10 \%)$ glutaraldehyde was added as the cross-linking agent, continuous stirring at $300 \mathrm{rpm}$ for $3 \mathrm{~h}$ to generate the polymeric beads. The resulted beads were washed several times with petroleum ether, ethanol and de-ionized water in sequence to remove any unreacted fraction and dried at $50{ }^{\circ} \mathrm{C}$ under vacuum for $24 \mathrm{~h}$.

\section{Preparation of cyanoethylated chitosan beads (CECB):}

Cross-linked chitosan beads (CLCB) $(5 \mathrm{~g})$ and acrylonitrile (AN) $(50 \mathrm{ml})$ were mixed in $100 \mathrm{ml}$ methanol then acetic acid $(0.2 \mathrm{ml}, 99.7 \%)$ was added to a flask supported with a magnetic stirrer and reflux. The reaction mixture was stirred at 300 $\mathrm{rpm}$ for $48 \mathrm{~h}$ and $75^{\circ} \mathrm{C}$ After cooling, CECB was filtered, washed several limes with ethanol and water and dried at $50{ }^{\circ} \mathrm{C}$ under vacuum for $24 \mathrm{~h}$.

\section{Synthesis of chitosan-amidoxime chelating resin (CACR):}

A suspension of CECB $(5 \mathrm{~g})$ and $\mathrm{NH}_{2} \mathrm{OH} . \mathrm{HCl}(4 \mathrm{gm})$ in $70 \mathrm{ml}$ methanol-water solution $(5: 1 \mathrm{v} / \mathrm{v})$ was added to a flask equipped with a magnetic stirrer and reflux condenser. About $15 \mathrm{ml}$ of $\mathrm{NaOH}$ aqueous solution $(7.5 \mathrm{M})$ was added to this mixture and the $\mathrm{pH}$ was kept at 8 . The above mixture was stirred for $48 \mathrm{~h}$ at $70 \mathrm{C}$. Finally, the resulted CACR beads was filtered out, washed several times with water and ethanol and dried at $50^{\circ} \mathrm{C}$ under vacuum for $24 \mathrm{~h}$ (Fig. 1).

\section{Preparation of aqueous solution}

A stock solutions of $\mathrm{Pb}$ ions was prepared by dissolving a known quantities of $\mathrm{Pb}\left(\mathrm{NO}_{3}\right)_{2} \cdot 4 \mathrm{H}_{2} \mathrm{O}$ in deionized water. The residual metals in solutions were analyzed using GBC atomic absorption reader (Model SavantAA AAS with Flame and GF 5000 Graphite Furnace). The $\mathrm{pH}$ adjustments were done using $1.0 \mathrm{M} \mathrm{NaOH}$ and 1.0 M HCl (APHA, 2005). 


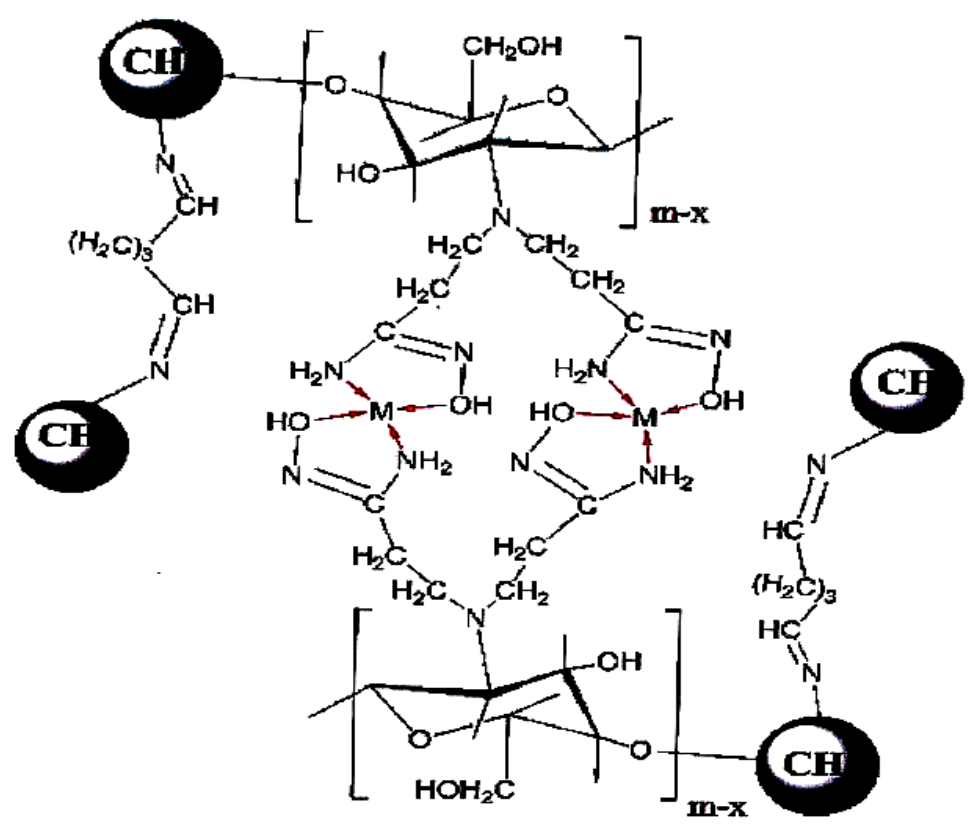

Fig. 1: Chelation of chitosan amidoxime chelating resin for metal ions.

\section{Characterization Technique:}

Fourier Transform infrared spectra (FTIR) of the prepared resins were obtained with an FTIR spectrometer (jasco 6100, Japan) in the $400-4000 \mathrm{~cm}^{-1}$ range. Thermal gravimetric analysis (DSC/TG) for prepared resin (CACR) was determined using NETZSCH STA 409 C/CD instrument, Germany. The experiment was carried out in a dynamic atmosphere of helium from room temperature to $70^{\circ} \mathrm{C}$ at heating rate of $10{ }^{\circ} \mathrm{C} / \mathrm{min}$ and a helium flow rate $1 \mathrm{ml} / \mathrm{min}$. BET surface area, before examination, the resin was put in vaccum at $300{ }^{\circ} \mathrm{C}$ for $2 \mathrm{~h}$ by means of adsorption of ultra-pure nitrogen at $77.35 \mathrm{k}$. The surface area was measured using the BrunauerEmmett-Teller (EBT) and BJH method based on adsorption data in the partial pressure $\left(\mathrm{P} / \mathrm{P}_{0}\right)$ range of $0.09-0.29$ the total pore volume was determined from the amount of the nitrogen adsorbed at $\mathrm{P} / \mathrm{P} 0=0.29729$.

\section{Batch adsorption studies}

All experiments were performed with $0.1 \mathrm{~g}$ resin in $250 \mathrm{ml}$ bottles with $50 \mathrm{ml}$ of single metal ion solution on a temperature controlled shaker $300 \mathrm{rpm}$, all experiments were carried out at $30{ }^{\circ} \mathrm{C}$ except the effect of temperature experiments. The desired $\mathrm{pH}$ of solution was adjusted using few drops of $0.1 \mathrm{M} \mathrm{HCI}$ and $0.1 \mathrm{M}$ $\mathrm{NaOH}$ solutions. A known volume $(50 \mathrm{~mL})$ each was pipette into the series of cultural vial to which $(1-5 \mathrm{~g} / \mathrm{l})$ of the [CACR] as adsorbent was added. Upon completion of the given contact time (10-300 min) between adsorbent and adsorbate, A detailed investigation on the initial concentration $(50-250 \mathrm{mg} / \mathrm{L})$, the solution $\mathrm{pH}$ (1.5-3.5) and temperature $\left(30-70{ }^{\circ} \mathrm{C}\right)$ on $\mathrm{Pb}$ metal ions removal from a solution was carried out. The removal percentage ( $\mathrm{R} \%$ ) can be calculated using the following equation (1):

$$
R \%=\frac{\left(C_{0}-C_{e}\right)}{C_{0}} \times 100
$$


Where $\mathrm{C}_{0}$ and $\mathrm{C}_{\mathrm{e}}$ are concentration $(\mathrm{mg} / \mathrm{l})$ of metal ions in the initial and equilibrium solutions, respectively. The equilibrium adsorption capacity $\left(\mathrm{q}_{\mathrm{e}}\right)$ of each sorbent was calculated using equation (2):

$$
q_{e}=\frac{\left(C_{0}-C_{e}\right) \mathbf{V}}{\mathbf{W}}
$$

Where, $\mathrm{q}_{\mathrm{e}}$ is the amount of metal ions adsorbed at equilibrium $(\mathrm{mg} / \mathrm{g}), \mathrm{V}$ is the volume of the initial solution taken at equilibrium (liter) and $\mathrm{W}$ is mass of the sorbent (gram) (Matthew et al 2003).

\section{RESULTS AND DISCUSSION}

\section{Characterization:}

\section{FT-IR Analysis:}

Fourier Transform Infrared absorption spectra of chitosan, CLCB, CECB and CACR were illustrated in Fig. (2-1). In the spectrum of pure chitosan, the - $\mathrm{OH}$ and $\mathrm{NH}_{2}$ (stretching vibration) groups are presented at peak $3491.11 \mathrm{~cm}-1$ (broad band). The C-O-C bridge absorption band (asymmetric stretching) was observed at 1421.06 $\mathrm{cm}^{-1}$, while skeletal vibration of C-O stretching corresponds to the bands at 1091.22 and $1189.14 \mathrm{~cm}^{-1}$ (De Vasconcelous et al. 2006). FT-IR spectrum of CLCB (Fig2-2) illustrates stretching vibration bands of $\mathrm{C}-\mathrm{H}$ (symmetric \& asymmetric) which enlarges at $2992.11 \& 2858.95 \mathrm{~cm}^{-1}$ and the peak at $1618.11 \mathrm{~cm}^{-1}$ is seen due to imine bonds $\mathrm{C}=\mathrm{N}$.

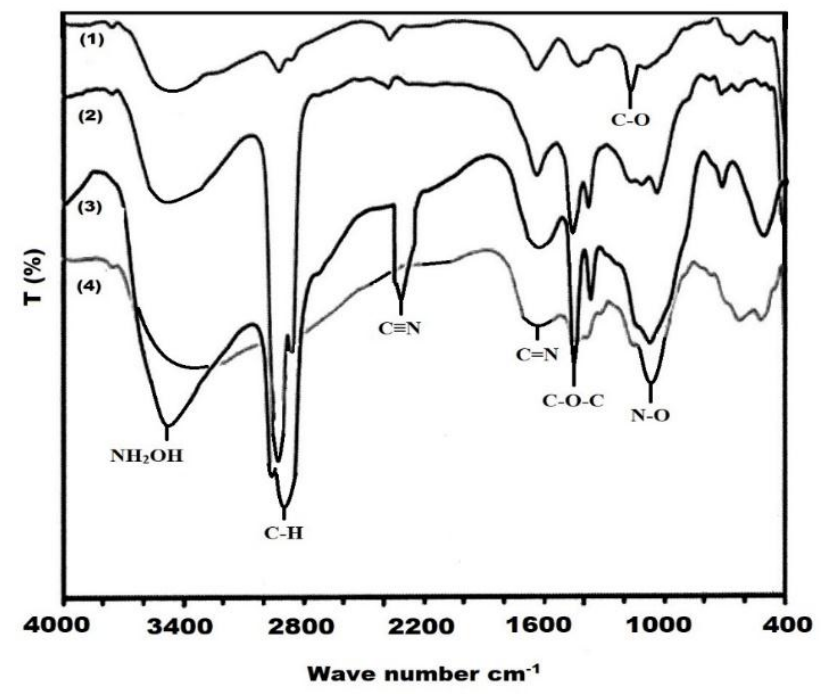

Fig. 2. FT-IR spectra of (1) pure chitosan (2) CLCB, (3) CECB and (4) CACR

After reaction with acrylonitrile, a new absorption band appears at $2742.01 \mathrm{~cm}^{-1}$ which is characteristic of the nitrile vibration band as shown in Fig.3c. Finally FTIR spectrum of CACR Fig.(2-3) revealed that the absorption band of the $\mathrm{C} \equiv \mathrm{N}$ group at $2360.78 \mathrm{~cm}^{-1}$ disappears and a new band at $1032.10 \mathrm{~cm}^{-1}$ appears due to vibration adsorption of the N-O bond in the amidoxime group (Bilba et al., 2004). 


\section{EDX analysis:}

The EDX spectrum (shown in Fig.3) further authenticates the presence of $\mathrm{N}$, oxygen and $\mathrm{Cl}^{-}$in the CACR, which demonstrated that $\mathrm{NH}_{2} \mathrm{OH} . \mathrm{HCl}$ was adsorbed onto The CECB to produce CACR beads.

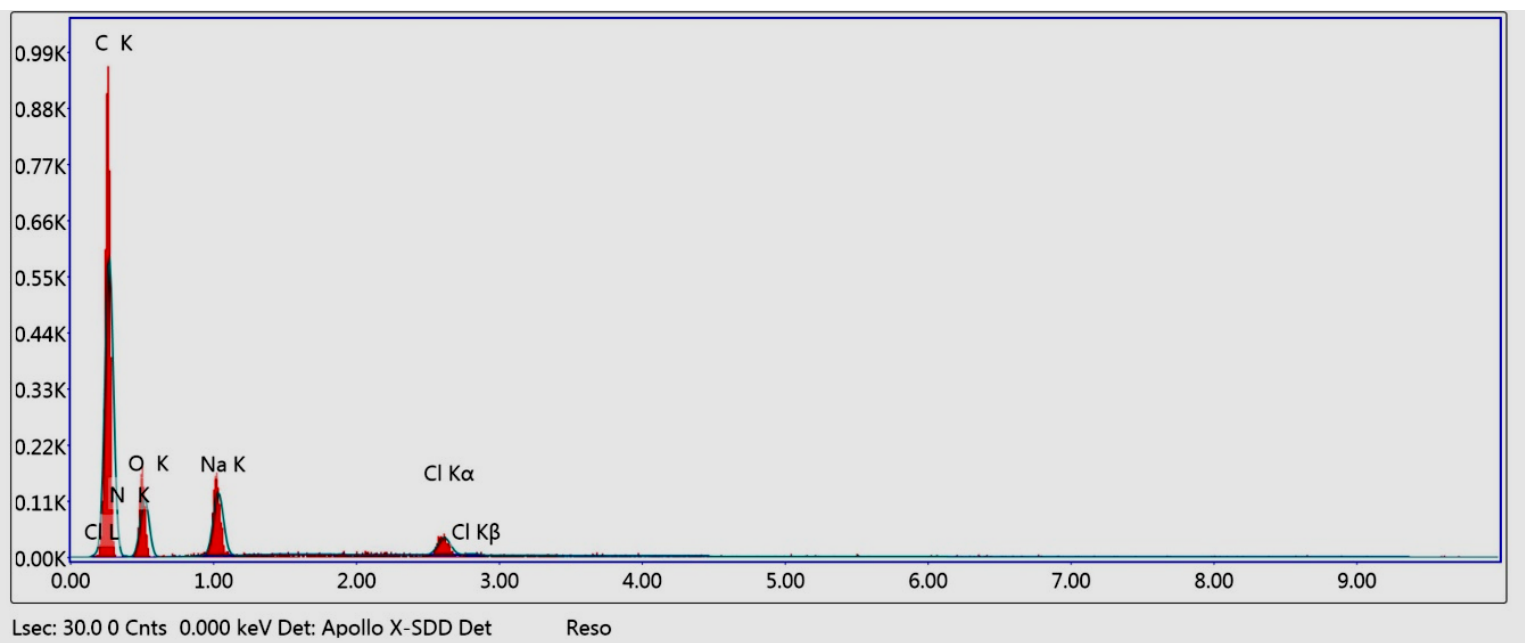

Fig. 3. EDX micrographs of CACR beads adsorption.

\section{Scanning Electron Microscope (SEM) analysis:}

Figure 4 shows the morphology of CACR before metal ion uptake indicates the clear empty cavities which can help for mass transfer of metal ions to its surface.

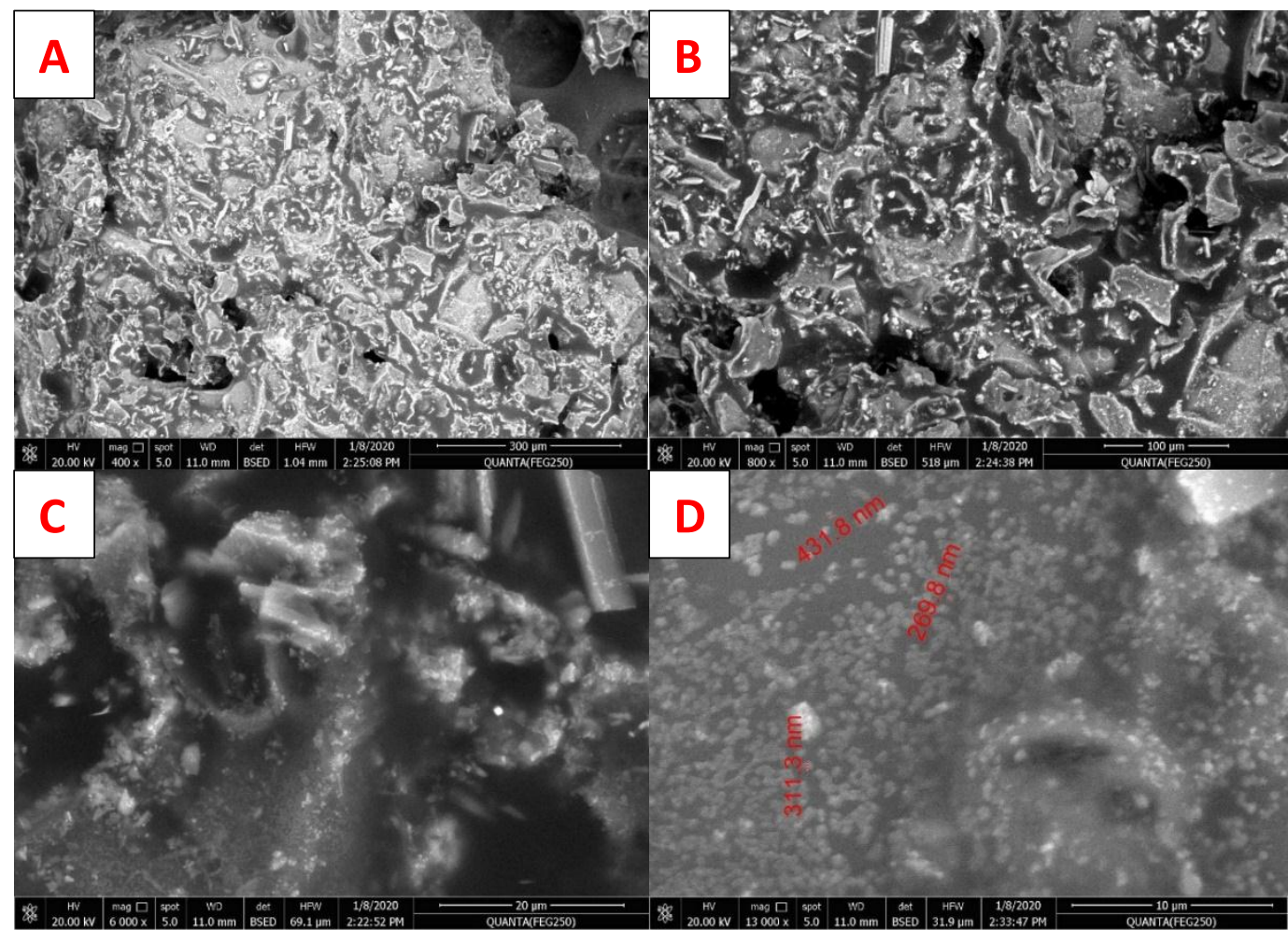

Fig. 4. Photo of CACR beads: (A) SEM image (x400), (B) SEM image (x800), (C) SEM image (x6000) and (D) SEM image (x13000) 


\section{BET surface area:}

The BET data show that the resin has a surface area of $39.52 \mathrm{~m} 2 / \mathrm{g}$ with a pore diameter of $2.981 \mathrm{~nm}$ which to be considered meso-porous structure and leads to the efficient transfer of the metal ions to the internal adsorption sites (Table 1).

Table 1. Porous structure parameters of CACR.

\begin{tabular}{lc}
\hline Parameters & Amidoxime \\
\hline BET surface area $\left(\mathrm{m}^{2} / \mathrm{g}\right)$ & 39.52 \\
\hline BJH desorption average pore diameter $(\mathrm{nm})$ & 2.981 \\
\hline BJH desorption cumulative volume of pores $\left(\mathrm{cm}^{3} / \mathrm{g}\right)$ & 0.1254 \\
\hline
\end{tabular}

\section{Batch Sorption Studies:}

\section{Effect of contact time on adsorption process:}

In order to determine the influence of contact time between CACR and the aqueous solution of $\mathrm{Pb}$ ions adsorption, variations of adsorption capacity (qe) Vs time (10-300 min) were plotted in Fig. (5). It was found that the adsorption of $\mathrm{Pb}$ ions is continuously increased with time increase until reaching equilibrium (qe $=50.6$ $\mathrm{mg} / \mathrm{gm}$ ) between two phases after $3 \mathrm{~h}$. Therefore, this optimum equilibrium time was selected for the next adsorption experiment.

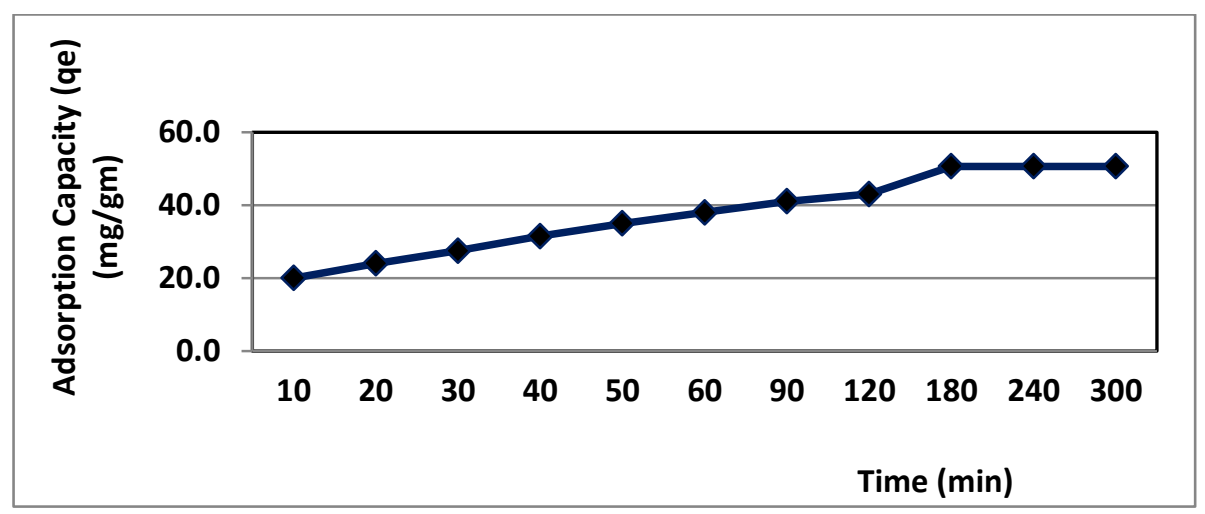

Fig. 5. Effect of contact time on the removal of $150 \mathrm{mg} / \mathrm{L}$ of lead using $2 \mathrm{gm} / \mathrm{L} \mathrm{CACR}$ at $\mathrm{pH} 3$

\section{Effect of initial contaminant concentration}

The effect of initial different lead ions concentration $(50,100,150,200 \& 250$ $\mathrm{mg} / \mathrm{L})$. At $2 \mathrm{gm} / \mathrm{L}$ of $[\mathrm{CACR}]$ was used. An influent solution with $\mathrm{pH}=3$ at temp. $=$ $30^{\circ} \mathrm{C} \pm 1$. Obtained results indicate that the amount of $\mathrm{Pb}$ (II) adsorbed onto CACR increased as the initial concentration of metal ions increased before reaching a plateau shape. Fig. (6) showed that the maximum adsorption capacity (qe) of $\mathrm{Pb}$ (II) reached $55.50(\mathrm{mg} / \mathrm{gm})$ at maximum initial concentration of $200(\mathrm{mg} / \mathrm{L})$. Further increasing of $\mathrm{Pb}$ ions to $300 \mathrm{mg} / \mathrm{l}$ led to decreasing the adsorption capacity. This may be due to the lack of available adsorbent sites at higher concentrations, and hence, the percentage adsorption of lead decreases, which agrees with those obtained by Srivastava and Sharma (2013).

\section{Mass of adsorbent:}

The effect of CACR mass on the removal lead ions from water has been studied to get the optimum conditions for the removal process. Different masses of Adsorbent $(1,2,3,4$ and $5 \mathrm{~g} / \mathrm{L})$ were applied for the removal of lead ions using solutions of 150 $\mathrm{mg} / \mathrm{L} \mathrm{Pb}$ ions a., $\mathrm{pH}=3$ and temp. $=30^{\circ} \mathrm{C} \pm 1$ (Fig. 7). 


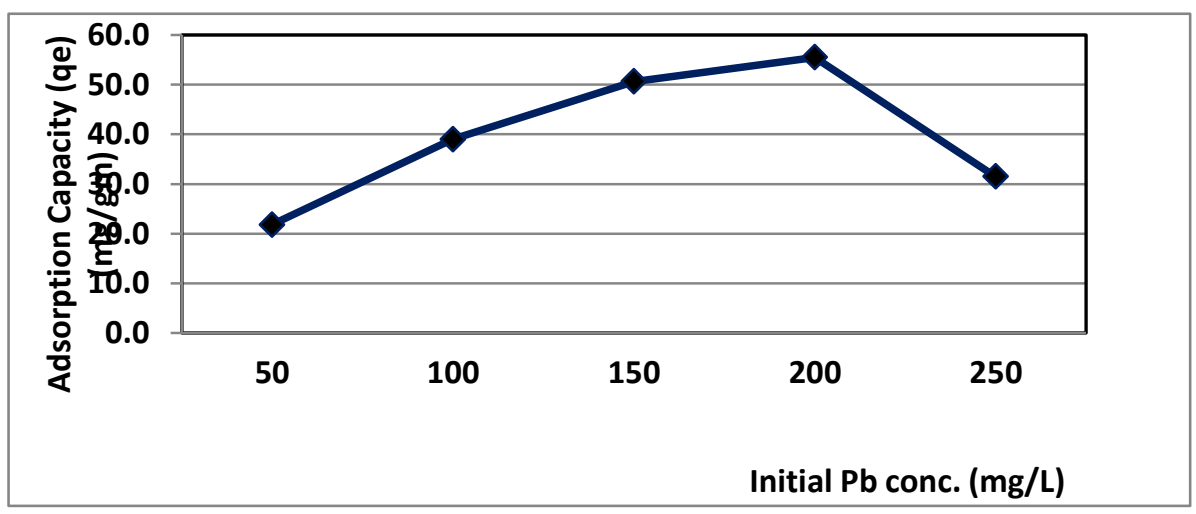

Fig. 6. Effect of initial concentration for removal of lead at using $2 \mathrm{gm} / \mathrm{L} \mathrm{CACR}$ at $\mathrm{pH} 3$ and contact time $180 \mathrm{~m}$

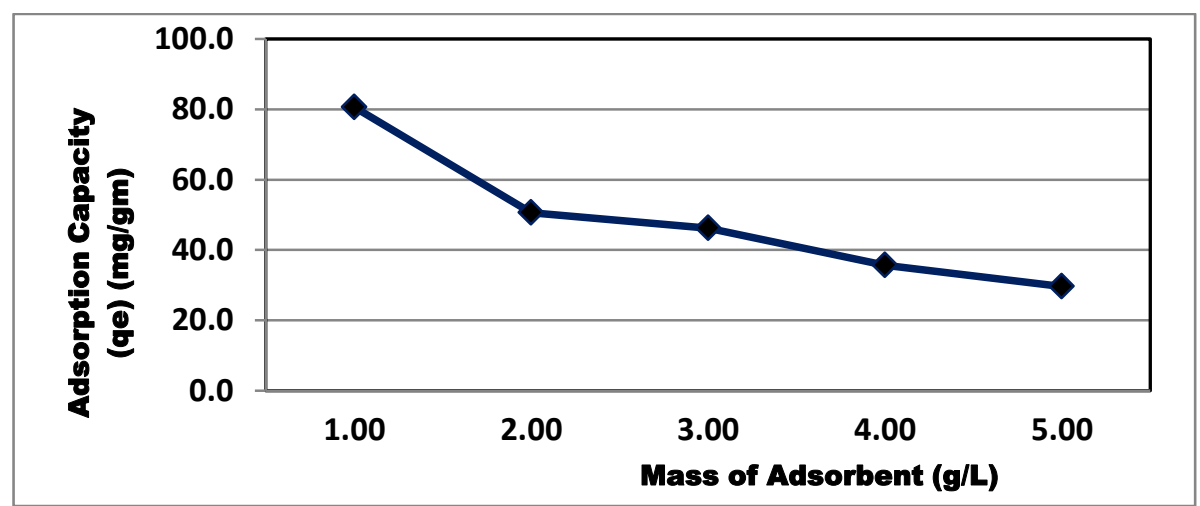

Fig. 7. Effect of Mass of CACR on removal of $150 \mathrm{mg} / \mathrm{L}$ of lead ions at $\mathrm{pH} 3$ and contact time $180 \mathrm{~m}$

The observations indicated that the variation in mass of CACR affects the removal of lead ions in such a way that as the mass of the CACR increase. Where the number of adsorption sites increase and consequently the removal of lead ions is improved. The determination of effect of adsorbent dosage gives an idea about the minimum amount of adsorbent need to be used for adsorption process. This value is useful in the viewpoint of cost (Gupta and Babu, 2010).

\section{Effect of solution $\mathrm{pH}$ :}

The $\mathrm{pH}$ of the solution is an important parameter, which controls the adsorption process. It influences the ionization of the adsorptive molecule and hence the surface charge of the adsorbent. The $\mathrm{pH}$ effect on the removal process of $150 \mathrm{ppm}$ lead ions. at $\mathrm{pH}=1.5,2,2.5,3$ and $\mathrm{pH}=3.5$. Using $0.1 \mathrm{gm}$ of [CACR] and the contact time was adjusted to be $120 \mathrm{~min}$ and temp. $=30^{\circ} \mathrm{C} \pm 1$ Fig.(8). The adsorption capacity (qe) values were 17.4, 92.5, 45.2, 47.7, 50.6 and $43.9 \mathrm{mg} / \mathrm{gm}$ for $\mathrm{pH}=1.5,2,2.5,3$ and $\mathrm{pH}=3.5$, respectively.

The variation of $\mathrm{pH}$ parameter showed remarkable effect on the removal process. All the consequent experiments were performed at $\mathrm{pH}$ 3. Above this optimum $\mathrm{pH}$, metal is precipitated as metal (II) hydroxide and the adsorption of these ions cannot be measured accurately. From the previous observations, we can concluded that the optimum condition to remove $\mathrm{Pb}$ from solution using 0.1 gram of [CACR] with adsorption efficiency up to $55.5 \mathrm{mg} / \mathrm{g}$, was recorded at , $\mathrm{pH} 3,200$ ppm of $\mathrm{Pb}$ ions in solution and contact time $180 \mathrm{~min}$. 


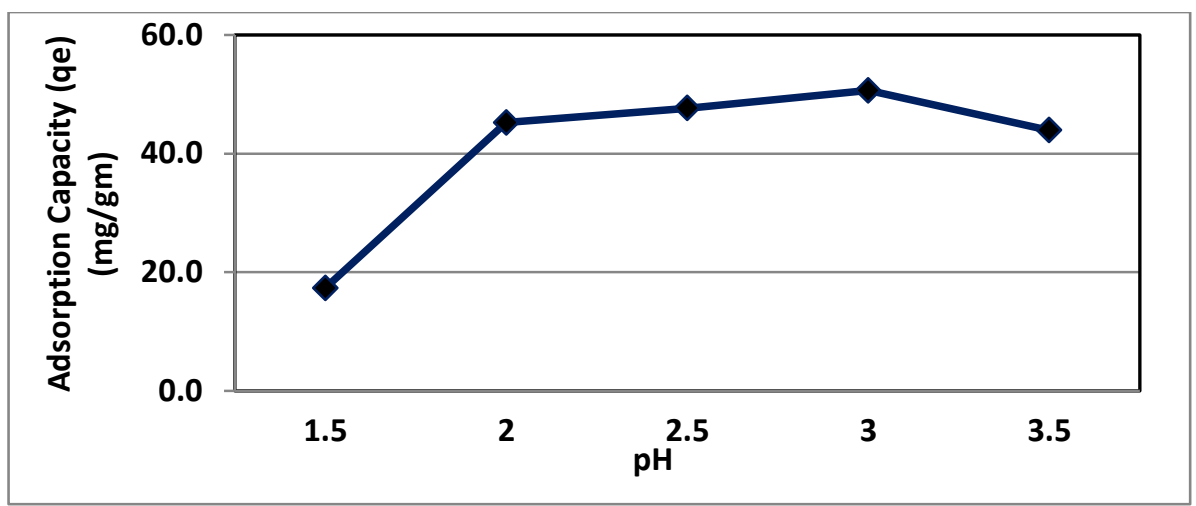

Fig. 8. Effect of $\mathrm{pH}$ value for removal of $150 \mathrm{mg} / \mathrm{L}$ of lead ions using $2 \mathrm{gm} / \mathrm{L} \mathrm{CACR}$ at $180 \mathrm{~m}$ contact time

\section{Effect of temperature:}

The influence of solution temperature on the adsorption capacity of $\mathrm{Pb}$ ions on CACR was examined, while other effective parameters were kept constant (contact time $180 \mathrm{~min}, 150 \mathrm{ppm}$ concentration, and $\mathrm{pH} 3$ ) Fig. (9).

The results indicates that the capacity is considerably increased by enhancing the solution temperature from 30 to $70^{\circ} \mathrm{C}$ in steps of to this enhancing of adsorption can be attributed to the fact at higher temperatures, cations move faster. This could be due to the fact that the specific or electrostatic interactions become weaker and the ions become smaller, since salvation is reduced (Abd El-Latif and ElKady, 2010). According to this explanation, it is clear that the adsorption of $\mathrm{Pb}$ (II) ions on the amidoxime chelating resin is an endothermic process.

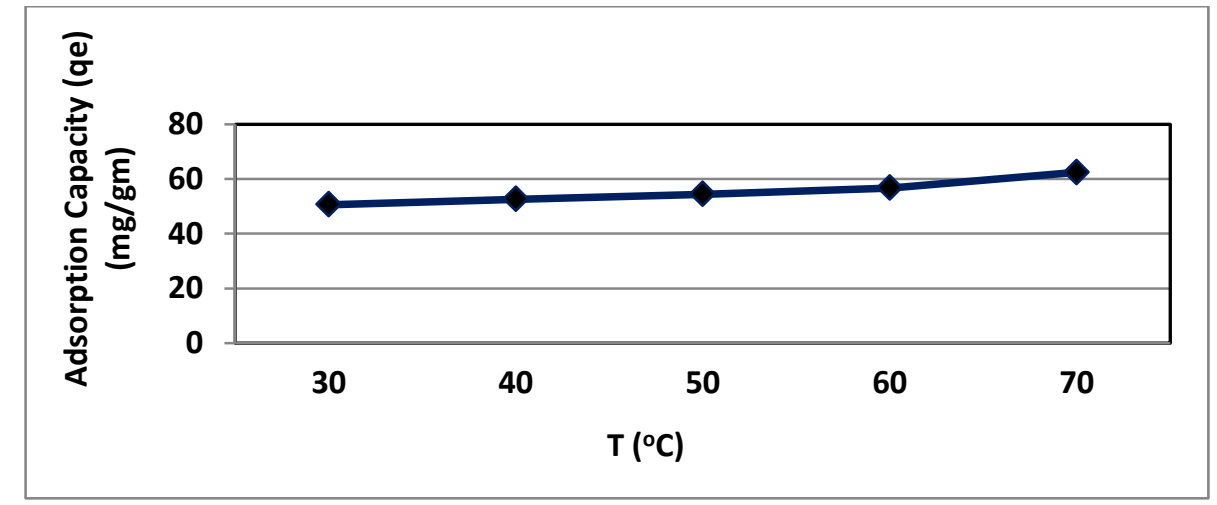

Fig. 9. Effect of temperature on the removal of $150 \mathrm{mg} / \mathrm{L}$ of lead ions using $2 \mathrm{gm} / \mathrm{L} \mathrm{CACR}$ at $\mathrm{pH} 3$ and

\section{Kinetic studies:}

180 min contact time

Kinetic performance of a given adsorbent is of at most important to get an indication about the solute uptake rate. It determines the residence time required to complete the adsorption reaction (Qiu, 2009). Due to the importance, the kinetic studies have been performed in majority of studies (Srivastava and Sharma, 2013). The pseudo First-order and pseudo second-order models developed by Ho and McKay (1998), connected with the reaction based models, two different kinetic models were applied to determine the mechanism involved in adsorption process. A relatively high $\mathrm{R}^{2}$ value indicates that the model successfully describes the adsorption kinetics (Fadali et al., 2005). 


\section{Pseudo-first-order kinetic model:}

The sorption kinetics may also be described by a pseudo first order equation (Özacar, 2003) is represented by the non-linear equation shown in equation (3):

$$
\frac{d q_{t}}{d t}=K_{1}\left(q_{e}-q_{t}\right)
$$

Where $\mathrm{q}_{\mathrm{e}}$ and $\mathrm{q}_{\mathrm{t}}$ is the lead concentrations in solid phase at equilibrium and at time $\mathrm{t}[\mathrm{mg} / \mathrm{g}]$, respectively. $\mathrm{K}_{1}$ is the rate constant for the pseudo-first-order adsorption process $[1 / \mathrm{min}]$. It can be simplified and expressed in linearized form as below equation (4):

$$
\log \left(q_{e}-q_{t}\right)=\log q_{e}-\frac{K_{1}}{2.303} t
$$

The equilibrium experimental data are plotted between $\log \left(\mathrm{q}_{\mathrm{e}}-\mathrm{q}_{\mathrm{t}}\right)$ and $\mathrm{t}$ as shown in Fig. (10) for the removal of lead. The correlation coefficients $\left(R^{2}\right)$ and the model parameters are evaluated and tabulated in Table (2).

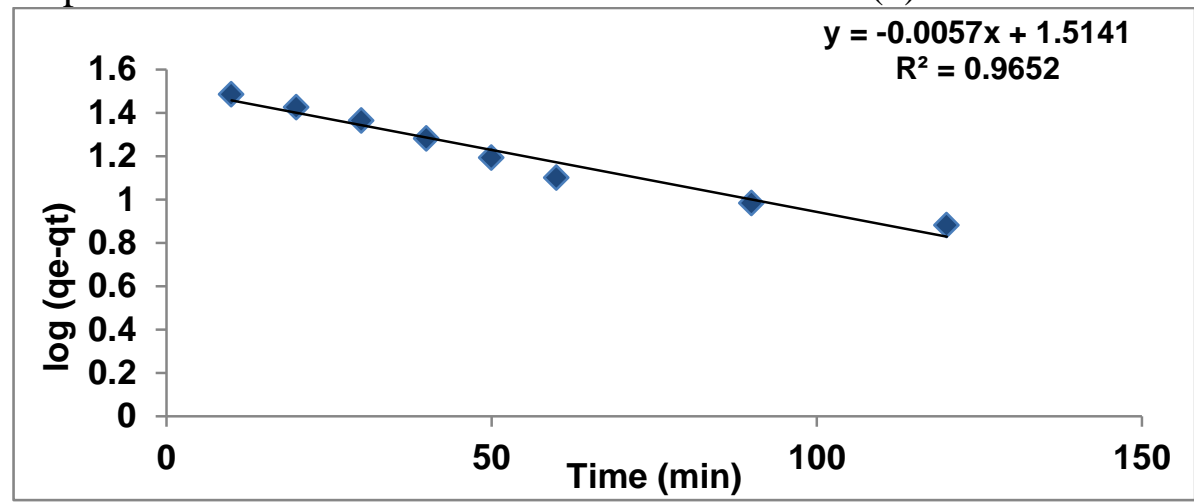

Fig. 10. Pseudo-first-order kinetic model plot for the removal of lead using CACR.

\section{Pseudo-second-order kinetic model}

A pseudo-second-order kinetic model is also utilized to explain the kinetic behavior of the operation. The applicability of the second-order kinetics is represented by the equation (5):

$$
\frac{d q_{t}}{d t}=K_{2}\left(q_{e}-q_{t}\right)^{2}
$$

Where $\mathrm{k}_{2}$ is the pseudo-second order rate constant of adsorption in $(\mathrm{g} / \mathrm{mg}$. $\mathrm{min})$, qe and qt is the amount of adsorbate adsorbed at equilibrium time and $t$ time respectively, in $(\mathrm{mg} / \mathrm{g})$ and $t$ is the contact time in minutes. It can be simplified and expressed in linearized form as below equation (6):

$$
\frac{t}{q_{t}}=\left(\frac{1}{K_{2} q_{e}^{2}}\right)+\left(\frac{1}{q_{e}}\right) t
$$

The equilibrium experimental data are plotted between $1 /\left(q_{e}-q_{t}\right)$ and $\mathrm{t}$ as shown in Fig. (11) for the removal of Lead. The correlation coefficients $\left(\mathrm{R}^{2}\right)$ and the model parameters are evaluated and tabulated in Table (2). 


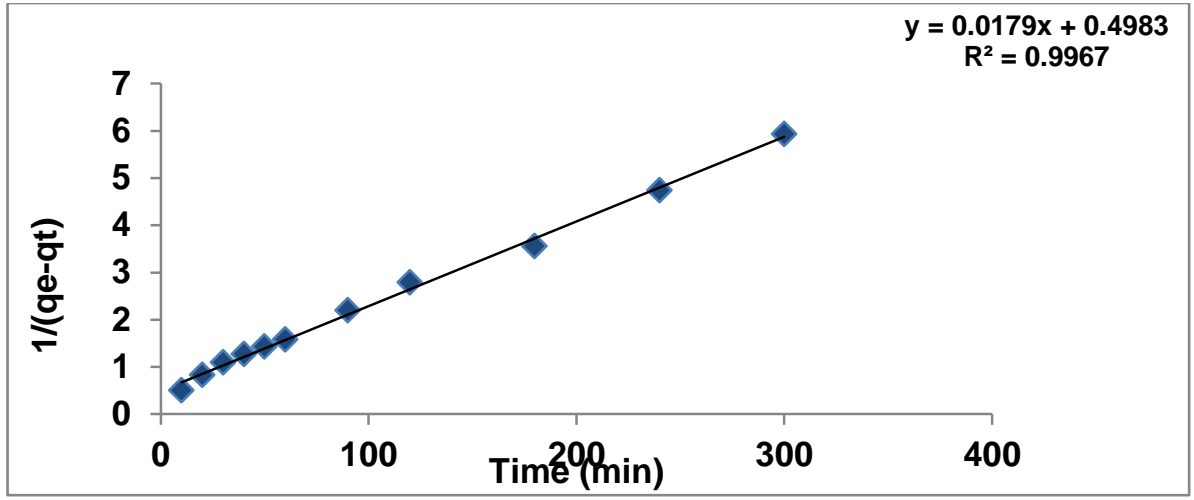

Fig. (11): Pseudo-second-order kinetic model plot for the removal of lead using CACR

Table (2): Kinetic parameters for the removal of lead using CACR

\begin{tabular}{|c|c|c|c|c|c|c|c|}
\hline \multicolumn{4}{|c|}{ Pseudo-First-Order kinetic model } & \multicolumn{4}{|c|}{ Pseudo-Second-Order kinetic model } \\
\hline $\begin{array}{c}\mathbf{K}_{\mathbf{1}} \\
(\mathbf{l} / \mathbf{m i n})\end{array}$ & $\mathbf{R}^{2}$ & $\begin{array}{c}\mathrm{q}_{\mathrm{e}} \text { Cal } \\
(\mathrm{mg} / \mathrm{gm})\end{array}$ & qexp & $\mathrm{K}_{2}$ (g/mg.min) & $\mathbf{R}^{2}$ & $\begin{array}{c}\mathbf{q}_{\mathrm{e}} \text { Cal } \\
(\mathrm{mg} / \mathrm{gm})\end{array}$ & qexp \\
\hline 0.01313 & 0.9652 & 32.67 & 50.60 & 0.00064301 & 0.9967 & 55.87 & 50.6 \\
\hline
\end{tabular}

Table (2) shows that the calculated adsorption capacities were 32.67 and 55.87 $\mathrm{mg} / \mathrm{g}$ and the of correlation coefficients $\left(\mathrm{R}^{2}\right)$ were 0.9652 and 0.9967 for pseudo-first order and pseudo-second order models, respectively compared to the experimental one of 50.60. Thus, the validation of the kinetic suggests the applicability of pseudosecond order kinetics for the adsorption of lead onto the CACR. As the surface functional groups become exhausted, the rate of sorption is controlled by the rate of transport from the external to the internal sites (Gupta and Babu, 2009).

\section{Adsorption isotherm model:}

Adsorption models of Langmuir (Langmuir, 1918) and Freundlich (Kalavathy et al. 2005) were applied to determine the relationship of lead adsorption with different induced concentration. The best-fitting isotherm was evaluated by linear regression, and the parameters obtained from the intercept and slope of the linear plots of these models (Lalhruaitluanga et al. 2010).

\section{Langmuir isotherm model:}

Estimation of maximum adsorption capacity corresponding to complete monolayer coverage on the resin was calculated using the Langmuir isotherm model, since the saturated monolayer isotherm can be explained by the non-linear equation of Langmuir equation (7):

$$
q_{e}=\frac{q_{\max } K_{a} C_{e}}{1+K_{a} C_{e}}
$$

The linearized Langmuir isotherm model is expressed as given in equation (8):

$$
\frac{1}{q_{e}}=\frac{1}{q_{\max }}+\left(\frac{1}{q_{\max } K_{a}}\right)\left(\frac{1}{C_{e}}\right)
$$

Where, qe is the amount of adsorbate at the time of equilibrium in $\mathrm{mg} / \mathrm{g}$. Ce is the equilibrium concentration of adsorbate in the solution in $\mathrm{mg} / \mathrm{L}, \mathrm{q}_{\max }$ is the maximum adsorption capacity in $\mathrm{mg} / \mathrm{g}$ (is the maximum quantity of adsorbate required to form a single monolayer on unit mass of adsorbent $\mathrm{mg} / \mathrm{g}$ ) and $\mathrm{Ka}$ is the Langmuir isotherm constant in $\mathrm{L} / \mathrm{mg}$ (adsorption equilibrium constant). As shown in Fig. (12) The equilibrium experimental data are plotted between 1/qe and 1/Ce. The 
correlation coefficients and the model parameters are evaluated and tabulated in Table (3).

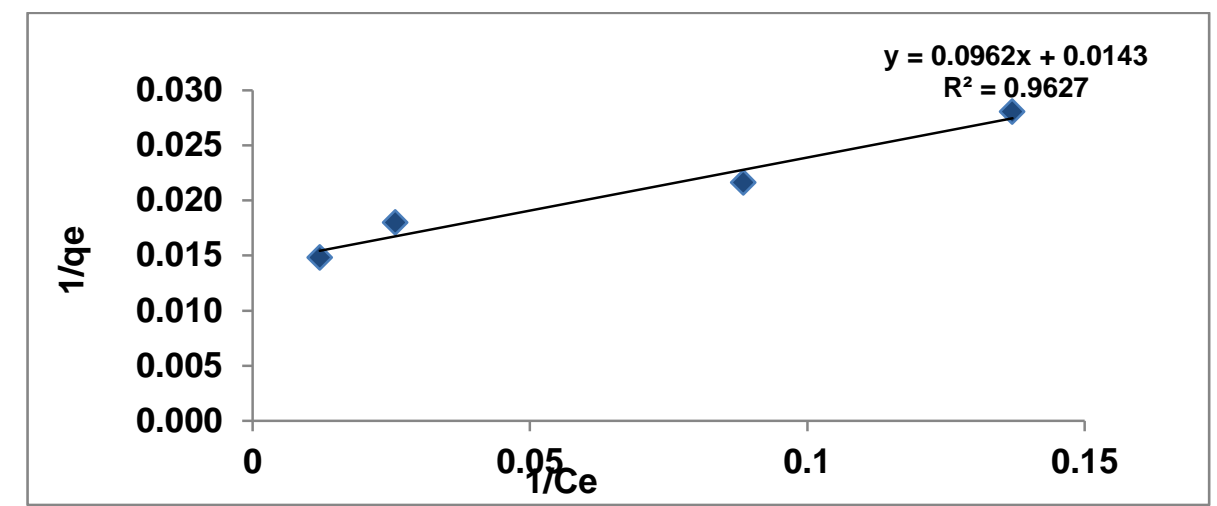

Fig. (12): Langmuir isotherm model plots for the removal of lead using CACR

The degree of suitability of CACR for the sorption of lead was also estimated from the values of the separation factor constant (RL) according to the following equation (9):

$$
R_{L}=(\mathbf{1}) /\left(\mathbf{1}+K_{a} C_{0}\right)
$$

The value of $\mathrm{RL}>1$ indicates unfavorable, $\mathrm{RL}=1$ linear, $0<\mathrm{RL}<1$ favorable or $\mathrm{RL}=0$ irreversible sorption. The RL value for the adsorption of lead on [CACR] is favorable and presented in Table (3).

\section{Freundlich isotherm model:}

The Freundlich model suggests a heterogeneous adsorption of the solute on the adsorbent surface (Gupta and Babu, 2010). The model Non-linear equation is expressed by the following equation (10):

$$
q_{e}=K_{f} C_{e}^{\frac{1}{n}}
$$

The Freundlich equation can be linearized and expressed as equation (11): (Kalavathy et al. 2005 ).

$$
\log q_{e}=\log K_{f}+\frac{1}{n} \log C_{e}
$$

Where $K_{F}$ is representing the Freundlich constant, which is indicating the relative adsorption capacity of the adsorbent related to the bonding energy in $\mathrm{mg} / \mathrm{g}$ and $\mathrm{n}$ is the heterogeneity factor representing the deviation from linearity of adsorption and is also known as Freundlich coefficient. $\mathrm{n}$ is the adsorption constant for Freundlich in L/mg, usually greater than one. It can be stated that, if the $1 / \mathrm{n}$ value is below unity, this implies that the adsorption process is chemical; if the value is above unity, adsorption is a favorable physical process (Gimbert, 2008). The experimental data are plotted between $\log$ qe and $\log$ Ce and shown in Fig. (13) for the removal of lead ions. The coefficients for Freundlich isotherm are evaluated and tabulated in Table (3). The sorption data fitted for both Langmuir and Freundlich isotherms with slightly advantage for the Langmuir approach. 


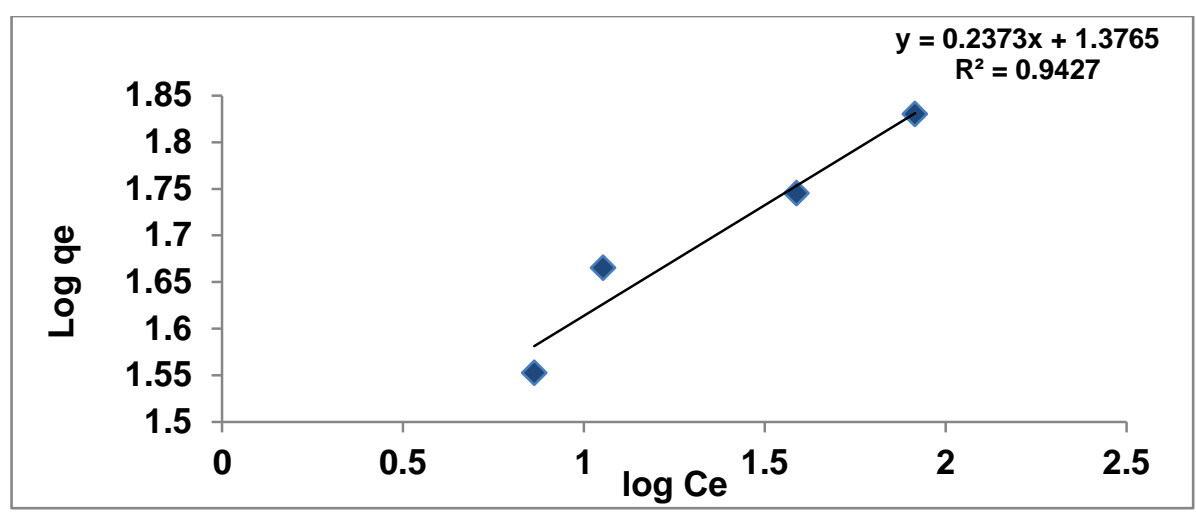

Fig 13. Freundlich isotherm model plots for the removal of lead ions using CACR.

Table 3. Isotherm parameters for the removal of lead using CACR

\begin{tabular}{cccc|cccc}
\hline \multicolumn{3}{c|}{ Langmuir isotherm model } & \multicolumn{4}{c}{ Freundlich isotherm model } \\
$\mathrm{Ka}$ & $\mathbf{R}^{2}$ & $\mathbf{R}_{\mathrm{L}}$ & $\mathbf{q m a x}$ & $\mathbf{n}$ & $\mathbf{R}^{2}$ & $\mathbf{K f}$ & $\mathbf{1} / \mathbf{n}$ \\
$\mathbf{0 . 1 4 9}$ & $\mathbf{0 . 9 6 2 7}$ & $\mathbf{0 . 0 4 3}$ & $\mathbf{6 9 . 9 3 0}$ & $\mathbf{4 . 2 1 4}$ & $\mathbf{0 . 9 4 2 7}$ & $\mathbf{2 3 . 7 9 6}$ & $\mathbf{0 . 2 3 7}$ \\
\hline
\end{tabular}

\section{CONCLUSION}

Chitosan amidoxime chelating resin (CACR) was used to remove $\mathrm{Pb}$ ions from aqueous solution. The batch experiment cited that the maximum adsorption efficiency

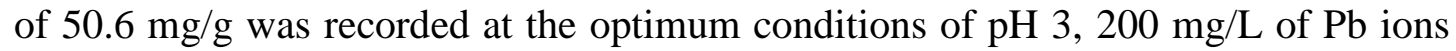
concentration and contact time $120 \mathrm{~min}$. using $2 \mathrm{gL} \mathrm{gm}$ of [CACR]. The adsorption of lead ions with [CACR] follows the pseudo second-order kinetics. The adsorption process was fitted to Langmuir and Freundlich adsorption isotherm models. The values of adsorption intensities $\left(0<\mathrm{R}_{\mathrm{L}}<1\right)$ indicate that the adsorption of lead with [CACR] is favorable and it is good sorbent for lead ions removal.

\section{REFERENCES}

Al-Wakeel K. Z.; Abd El Monem, H. and Khalil M. M.H. (2015). Removal of divalent manganese from aqueous solution using Glycine Modified Chitosan Resin. J. Environm. Chem. Engineering 3: 179-186.

Abd El-Latif, M.M. and ElKady, M.F. (2010). Equilibrium isotherms for harmful ions sorption using nana zirconium vandate ion exchanger. Desalination. 255: 21.

APHA (2005). Standard methods for the examination of water and wastewater. 21st edition. American Public Health Association, Washington, DC.

Bailey, S.E; Olin, T.J.; Bricka, R.M. and Adrian, D.D. (1999). A review of potentially low-cost sorbents for heavy metals, Water Res. 33:2469-2479.

Bilba, N.; Billa, D. and Morroi, G. (2004). Synthesis of a polyacrylamidoxime chelating fiber and its efficiency in the retention of palladium ions. J. Appl.polyb. sci. 92, Appl.polyb. sci. 92:3730-3735.

Bingjie L.; Dongfeng W.; Guangli Y.; and Xianghong M. (2013). Removal of Ffrom aqueous solution using $\mathrm{Zr}(\mathrm{IV})$ impregnated dithiocarbamate modified chitosan beads, Chemical Engineering Journal 228 (2013) 224-231.

Curkovic, L.; Stefanovic, S.C. and Filipan, T. (1997). Metal ion-exchange by natural and modified zeolites, Water Res. 31:1379-1382.

De Vasconcelous, C.L.; Bezerril, B.M.; dos Santos, D. E. S. ; Dants, T. N. C.; Pereira, M. R. and Fonseca, J.L.C. (2006). Effect of molecular weight and ionic 
strength on formation of polyelectrolyte complexes based on poly(methacrylic acid) and chitosan, Biomacromolecules. 7:1245-1252.

Fadali, O. A.; Ebrahiem, E. E.; Magdy, Y. H.; Daifullah, A. A. M. and Nassar, M. M. (2005). Removal of Chromium from Tan-nery Effluents by Adsorption. Journal of Environmental Science and Health, Part A: Toxic/Hazardous Substances and Envi-ronmental Engineering, 39(2): 465-472.

Gimbert, F. (2008). Adsorption isotherm models for dye removal by cationized starch-based material in a single component system: error analysis. J Hazard Mater, 157(1): 34-46.

Gupta, S and Babu, B.V. (2009). Utilization of waste product (tamarind seeds) for the removal of $\mathrm{Cr}(\mathrm{VI})$ from aqueous solutions: Equilibrium, kinetics, and regeneration studies, J Environ Manag 90(10):3013-3022. doi:10.1016/j.jenvman.2009.04.006

Gupta, S. and Babu, B. V. (2010). Experimental, kinetic, equilibrium and regeneration studies for adsorption of $\mathrm{Cr}(\mathrm{VI})$ from aqueous solutions using low cost adsorbent (activated flyash), Desalin Water Treat 20(1-3):168-178. doi:10.5004/dwt.2010.1546.

Ho, Y.S. and McKay, G. (1998). Sorption of dye from aqueous solution by peat, Chem. Eng. J., 70:115-124.

Kalavathy, M. H.; Karthikeyan, T.; Rajgopal, S. and Miranda, L.R. (2005). Kinetic and iso-therm studies of $\mathrm{Cu}$ (II) adsorption onto H3PO4-activated rubber wood sawdust. Journal of Colloid Interface Science, 292 (2): 354-362.

Karthikeyan, G.; Anbalagan, K. and Muthulakshmi Andal, N. (2004). Adsorption dynamics and equilibrium studies of $\mathrm{Zn}$ (II) onto chitosan. Journal of chem. Sci., 116:119-127.

Khalil M. M.; Al-Wakeel, K. Z.; Abd El Rehim S. S. and Abd El Monem H. (2014). Adsorption of $\mathrm{Fe}$ (III) from Aqueous Medium onto Glycine-Modified Chitosan Resin: Equilibrium and Kinetic Studies. Journal of Dispersion Science and Technology 35 1691-1698.

Kurniawan, T. A.; Chan, G.Y.S.; Lo, W.H. and Babel, S. (2006). Physico-chemical treatment techniques for wastewater laden with heavy metals, Chemical Engineering Journal, 118: 83-98.

Lakherwal, D. (2014). Adsorption of Heavy Metals A Review.pdf. International Journal of Environmental Research and Development, 4(1): 41-48.

Lalhruaitluanga, H.; Jayaram, K.; Prasad, M. N. V. and Kumar, K. K. (2010). Lead (II) adsorption from aqueous solutions by raw and activated charcoals of Melocanna bac-cifera Roxburgh (bamboo)-A comparative study, Journal of Hazardous Materials, 175 (1-3): 311-318.

Lalhruaitluanga, H.; Jayaram, K.; Prasad, M.N.V. and Kumar, K.K. (2010). Lead (II) adsorption from aqueous solutions by raw and activated charcoals of Melocanna bac-cifera Roxburgh (bamboo)-A comparative study. Journal of Hazardous Materials, 175 (1-3)|: 311-318.

Langmuir, I. (1918). The Adsorption of Gases on Plane Surfaces of Glass, Mica and Platinum. Journal of American Chemical So-ciety, 40: 1361-1403.

Matthew, J.; Sengupta, A. and Greenleaf, J. (2003). Arsenic removal using a polymeric / inorganic hybrid sorbent, Water Research, 37(1): 164-176. DOI: 10.1016/S0043-1354(02)002.

Nadeem, M.; Nadeem, R.; Nadeem, H.U. and Shah, S.S. (2005). Accumulation of lead and cadmium in different organs of chicken, Pak. J. Sci. Res. 57: 71. 
Özacar, M. (2003). Equilibrium and Kinetic Modeling of Adsorption of Phosphorus on Calcined Alunite. Adsorption, 9(2): 125-132.

Patterson, J.W. (1985). Industrial Wastewater Treatment Technology, Butterworth Publishers, Stoneham, USA.

Pentari, D.; Perdikatsis, V.; Katsimicha, D. and Kanaki, A. (2009). Sorption properties of low calorific value Greek lignites: removal of lead, cadmium, zinc and copper ions from aqueous solutions. J. Hazard. Mater, 168:1017-1021.

Qiu, H. (2009). Critical review in adsorption kinetic models. Journal of Zhejiang University Science A, 10(5): 716-724.

Ramos, R.L.; Jacome, L.A.B.; Barron, J.M.; Rubio, L.F. and Coronado, R.M.G (2002). Adsorption of zinc(II) from an aqueous solution onto activated carbon, J. Hazard. Mater. 90:27-38.

Ramya, R.; Shanmugapriyal, A.; Ramasubramaniam, S. and Sudha, P.N. (2011a). Studies on removal of $\mathrm{Cr}$ (VI) and $\mathrm{Cu}$ (II) ions using chitosan graftedpolyacrylonitrile. Scholar research library, 3:423-435.

Ramya, R.; Sankar, P.; Anbalagan, S. and Sudha, P.N. (2011b). Adsorption fo Cu (II) and $\mathrm{Ni}$ (II) ions from metal solution using crosslinked chitosan-g-acrlonitrile copolymer. International journal of environmental science, 1:1323-1338.

Saha, P.; Datta, S. and Sanyal, S.K. (2008). Study on the Effect of Different Metals on Soil Liner Medium, Indian Sci. Cruiser, 22:50-56.

SenGupta, A. K.; DeMarco, M. J. and Greenleaf, J. E. (2003). Arsenic removal using a polymeric/inorganic hybrid sorbent, Water Research, 37: 164-176.

Srivastava, V. and Sharma, Y.C. (2013). Synthesis and Characterization of Fe3O4@n-SiO2 Nanoparticles from an Agrowaste Material and Its Application for the Removal of Lead from Aqueous Solutions, Water, Air, \& Soil Pollution, 225(1).

Wan Ngah, W.S. and Hanafiah, M.A.K.M. (2008). Removal of heavy metal ions from wastewater by chemically modified plant wastes as adsorbents: A review, Bioresource Technology, 3935-3948.

Wana, M.W.; Kan, C.; Buenda, D.; Rogel, b. and Lourdesp, M. (2010). Adsorption of copper (II) and lead (II) ions from aqueous solutions on chitosan coated sand. Dalida carbohydrate polymers, 80:891-899.

Wang, D. F.; Liu, B. J.; Xu, Y.; Zhang, L.; Li, H. Y.; Yao, H. K. (2010). Chinese patent: 201010119859.6.

WHO (2011). Guidelines for Drinking Water Quality-Fourth Edition. World Health Organization, Geneva.

Yadla, S.V.; Sridevi, V. and Chandana Lakshmi, M.V.V. (2012). A review on adsorption of heavy metals from aqueous solution. Journal of chemical, biological and physical science, 2:1585-1593. 